Document downloaded from:

http://hdl.handle.net/10251/122863

This paper must be cited as:

Benajes, J.; García Martínez, A.; Monsalve-Serrano, J.; Lago-Sari, R. (2018). Experimental investigation on the efficiency of a diesel oxidation catalyst in a medium-duty multi-cylinder $\mathrm{RCCl}$ engine. Energy Conversion and Management. 176:1-10.

https://doi.org/10.1016/j.enconman.2018.09.016

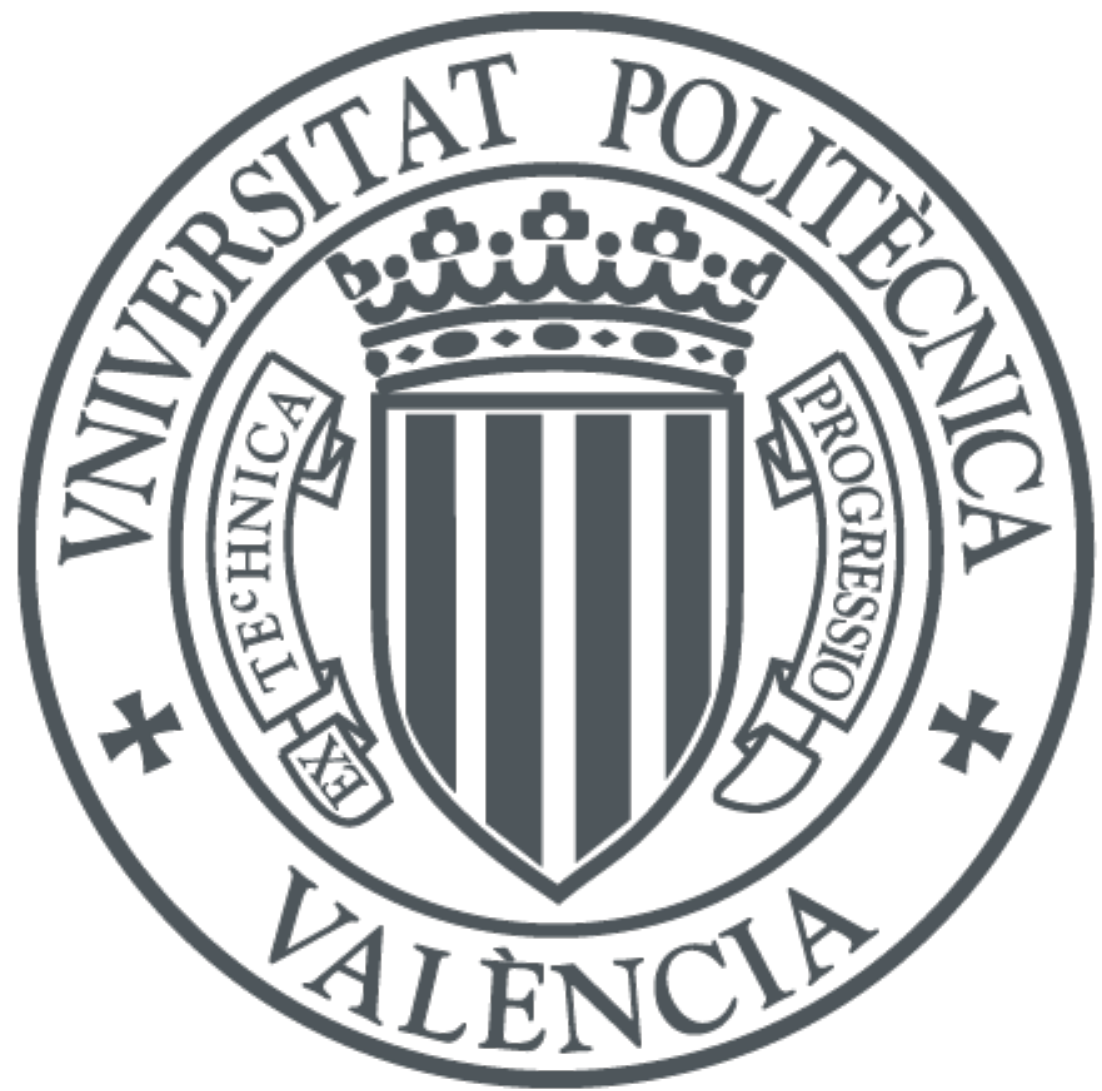

The final publication is available at

https://doi.org/10.1016/j.enconman.2018.09.016

Copyright Elsevier

Additional Information 


\title{
Experimental investigation on the efficiency of a diesel oxidation catalyst in a medium-duty multi-cylinder $\mathrm{RCCl}$ engine
}

Energy Conversion and Management, Volume 176, 15 November 2018, Pages 1-10

https://doi.org/10.1016/j.enconman.2018.09.016

Jesús Benajes, Antonio García*, Javier Monsalve-Serrano and Rafael Lago Sari

CMT - Motores Térmicos, Universitat Politècnica de València, Camino de Vera s/n, 46022 Valencia, Spain

Corresponding author $(*)$ :

Dr. Antonio García Martínez (angarma8@mot.upv.es)

Phone: +34 963876574

Fax: +34963876574

\begin{abstract}
Reactivity controlled compression ignition ( $\mathrm{RCCl}$ ) combustion is one of the most promising low temperature combustion (LTC) techniques, as it is able to provide ultralow NOx and soot emissions together with higher thermal efficiency than conventional diesel combustion $(C D C)$ in a wide range of operating conditions. However, the unburned hydrocarbon (UHC) and carbon monoxide (CO) emission levels are orders of magnitude higher than $\mathrm{CDC}$, which can result in a major problem for implementing the $\mathrm{RCCl}$ concept in real engines. In this sense, the high levels of UHC and CO emissions together with the low exhaust temperatures during $\mathrm{RCCl}$ operation could compromise the diesel oxidation catalyst (DOC) conversion efficiency.

The objective of this work is to evaluate the efficiency of a conventional DOC in oxidizing the UHC and $\mathrm{CO}$ emissions from $\mathrm{RCCl}$ combustion. To do this, a medium-duty multicylinder diesel engine equipped with its original after treatment system has been used. First, the DOC conversion efficiency is evaluated under some steady-state conditions. Later, the influence of the thermal inertia on the DOC response has been evaluated by means of transient tests. In this sense, different engine load-speed steps as well some simplified conditions from the worldwide harmonized vehicle cycle (WHVC) and the supplemental engine transient cycle (SET) are evaluated. In steady-state conditions, with DOC-inlet temperatures of $200-300^{\circ} \mathrm{C}$, the results show conversion efficiencies of $100 \%$ for CO and $85-95 \%$ for HC. At $10 \%$ and $25 \%$ load, the DOC-outlet UHC levels are unacceptable considering the EURO VI regulation, while at $50 \%$ load the tailpipe emissions fulfill the emissions standard. The results in transient conditions are more promising thanks to effect of the thermal inertia, showing $100 \%$ conversion efficiency for $\mathrm{CO}$ and greater than $90 \%$ for UHC during large periods of engine operation.
\end{abstract}

\section{Keywords}

Reactivity controlled compression ignition; Dual-fuel combustion; Aftertreatment; Catalyst; Emissions 


\section{Introduction}

During the last years, the emissions regulations for internal combustion engines (ICE) are being more and more stringent with the aim of reducing the levels of pollutants emitted to the atmosphere [1][2]. In the transport sector, compression ignition (CI) engines are the most widely used ICE type because they provide high efficiency with moderate engine-out emissions [3]. The most harmful emissions from $\mathrm{Cl}$ engines operating with diesel fuel are the nitrogen oxides (NOx) and soot. Between both pollutants exists a trade-off by which reducing one, the other increases [4]. To reduce both pollutants simultaneously, the current $\mathrm{Cl}$ are equipped with aftertreatment devices that reduce the emissions before being emitted to the atmosphere. The most used technologies in the $\mathrm{Cl}$ used for transport sector are the selective catalyst reduction (SCR) to reduce NOx, and the diesel particulate filter (DPF) for soot emissions [5][6]. The use of these devices increases both the acquisition and operation costs for the customer. The operation costs increase due to several reasons, as are the necessary maintenance, exhaust fluids consumption, an extra back pressure in the exhaust line [7][8].

The aftertreatment systems are being continuously improved to increase their efficiency and reduce their associated costs [9]. In parallel to this, the research community is working on developing new combustion strategies to reduce the generation of pollutant emissions during the combustion process. This allows minimizing the aftertreatment necessities to meet the current standards [10]. The low temperature combustion (LTC) strategies have been confirmed as able to provide ultra-low engine-out NOx and soot emissions and similar efficiency than CDC [11][12]. The formation of both pollutants is reduced simultaneously by using high amounts of EGR rates together with highly advanced injection strategies, which improves the fuel-air mixing before the start of combustion [13][14]. Moreover, the thermodynamic efficiency of the engine cycle increases due to the heat transfer reduction and the lower combustion duration [15].

Among the different LTC concepts, the reactivity controlled compression ignition (RCCI) combustion is the most widely studied strategy nowadays because it offers high efficiency and low NOx and soot emissions in a wide engine operating range [16]. RCCl is implemented by feeding the engine with two fuels of different reactivity, as diesel (high reactivity fuel, HRF) and gasoline (low reactivity fuel, LRF), using independent injection systems [17]. The diesel fuel is injected directly into the cylinder, while the gasoline is fumigated in the intake port [18]. This allows modifying the percentage of each fuel injected according to the engine operating conditions. As described in literature, a highly efficient operation can be promoted using a major portion of LRF, and using the HRF to trigger the combustion [19][20]. After the start of combustion, its progression strongly depends on the in-cylinder reactivity stratification, mainly driven by the HRF injection conditions [21]. The reactivity gradient leads to a more sequential autoignition than other LTC concepts [22], reducing the maximum pressure rise rate (PRR) at high loads.

Recent works performed on different engine platforms confirm the potential of RCCI on reaching engine-out NOx and soot levels below the limits imposed by the EURO VI regulation in steady-state conditions [23][24]. Nevertheless, RCCI still has several challenges that limit its practical application [25][26], as are the high EGR rate levels needed to enable operation at high load [27][28] and the high amount of UHC and CO 
emitted at low load [29][30]. An alternative to apply RCCl in all the engine map is the dual-mode concept, which consists of switching to another combustion regime in the regions of the map in which the $\mathrm{RCCl}$ has limitations [31]. Depending on the engine compression ratio $(\mathrm{CR})$, the secondary combustion mode used to complete the engine map can change, e.g. switching to diffusive dual-fuel [32] or to CDC [33].

The dual-mode dual-fuel (DMDF) strategy can be implemented with lower CR than the dual-mode $\mathrm{RCCl} / \mathrm{CDC}$ concept. This allows extending the operating region of $\mathrm{RCCl}$ towards higher loads in the global map before the PRR problems start to appear. However, the UHC and CO emissions levels at low and medium loads with DMDF are higher than with dual-mode RCCI/CDC, and much higher than with $\mathrm{CDC}$ [34]. This occurs because the majority of engine operating conditions found during a real driving cycle fall in the low-medium load portion of the map, where $\mathrm{RCCl}$ operation is promoted. This fact can cause difficulties for the DOC to operate in a high efficient region, even more considering the low exhaust temperatures with RCCl. Additionally, the chemical composition of the exhaust gas has a great dependence on the engine operating condition since the gasoline fraction (GF) varies substantially along the RCCI map.

In a preliminary work [35], the authors developed a DOC model for $\mathrm{RCCl}$ combustion using data coming from experimental measurements in a single-cylinder light-duty engine equipped with a conventional DOC (sized for four cylinders). Under these conditions, the results suggested that the DOC volume needed to fulfill the type approval regulation limits for different driving cycles ranges from four to six times the original volume, mainly because of the low UHC conversion efficiency. However, some effects such as the thermal inertia were not perfectly characterized due to using a single-cylinder engine, which may have a great influence in the DOC sizing.

The objective of this work is to evaluate the efficiency of a conventional DOC in oxidizing the $\mathrm{UHC}$ and $\mathrm{CO}$ emissions from $\mathrm{RCCl}$ combustion in a series-production engine architecture working in steady-state and transient conditions. To do this, a medium-duty multi-cylinder diesel engine equipped with its original aftertreatment system has been used. First, the DOC conversion efficiency is evaluated under some steady-state conditions. Later, the influence of the thermal inertia on the DOC response has been assessed by means of transient tests. In this sense, different engine load-speed steps as well some simplified conditions from the worldwide harmonized vehicle cycle (WHVC) and the supplemental engine transient cycle (SET) are evaluated.

\section{Materials and methods}

\subsection{Engine characteristics}

The experimental tests were carried out on a medium-duty, four stroke, serial production $8 \mathrm{~L}$ multi-cylinder diesel engine (MCE). The engine has a dedicated piston with bathtub bowl shape, optimized for $\mathrm{RCCl}$ combustion [24]. The geometric compression ratio is $12.75: 1$. Table 1 shows the main characteristics of the engine. 
Table 1. Engine characteristics.

\begin{tabular}{|c|c|}
\hline Engine Type & 4 stroke, 4 valves, direct injection \\
\hline Number of cylinders [-] & 6 \\
\hline Displaced volume $\left[\mathrm{cm}^{3}\right]$ & 7700 \\
\hline Stroke $[\mathrm{mm}]$ & 135 \\
\hline Bore $[\mathrm{mm}]$ & 110 \\
\hline Piston bowl geometry [-] & Bathtub \\
\hline Compression ratio [-] & $12.75: 1$ \\
\hline Rated power [kW] & $235 @ 2100 \mathrm{rpm}$ \\
\hline Rated torque [Nm] & $1200 @ 1050-1600$ rpm \\
\hline
\end{tabular}

\subsection{Test cell description}

A scheme of the test cell in which the multi-cylinder engine was installed is shown in Figure 1 . The engine speed and load were governed through an electric dynamometer. The pressure and temperature of the intake charge was monitored before and after the high-pressure exhaust gas recirculation (EGR) line. The original exhaust line was modified to include a low-pressure EGR line, including a cooler and a filter. Moreover, a pneumatic valve was installed downstream the turbine to regulate the low-pressure EGR flow. The exhaust temperature and pressure were controlled at the exhaust manifold as well as at different points of the exhaust line. The original aftertreatment system (ATS) box, composed of a DOC, DPF and SCR, was installed after the pneumatic valve, 1300 $\mathrm{mm}$ far from the exhaust manifold. As shown in Figure 1, pressure and temperature transducers were instrumented at different points of the ATS. The geometrical parameters of the DOC used in this work are listed in Table 2. The gaseous engine-out emissions were measured before and after the DOC using a five-gas Horiba MEXA-7100 DEGR analyzer. The data of each condition was recorded along a period of 60 seconds, and repeated three times. The three repetitions were recorded first with the emissions probe set upwards the DOC. After that, the three measurements were carried out with the emissions probe placed downwards the DOC. Then, the combustion efficiency can be estimated as shown in Equation 1 [36].

$$
\text { Comb.Eff. }=\left(1-\frac{H C}{m_{f}}-\frac{C O}{4 \cdot m_{f}}\right) \cdot 100
$$

An AVL 415S smoke meter was used to measure the black carbon content in the exhaust stream, providing the results in filter smoke number (FSN) units. Each operating condition was measured three times, with a sample volume of 1 liter and paper-saving mode off [37]. An in-house developed acquisition system (SAMARUC) was used to record the low frequency variables at $100 \mathrm{~Hz}$. Table 3 summarizes the precision of the most important components of the test bench. 


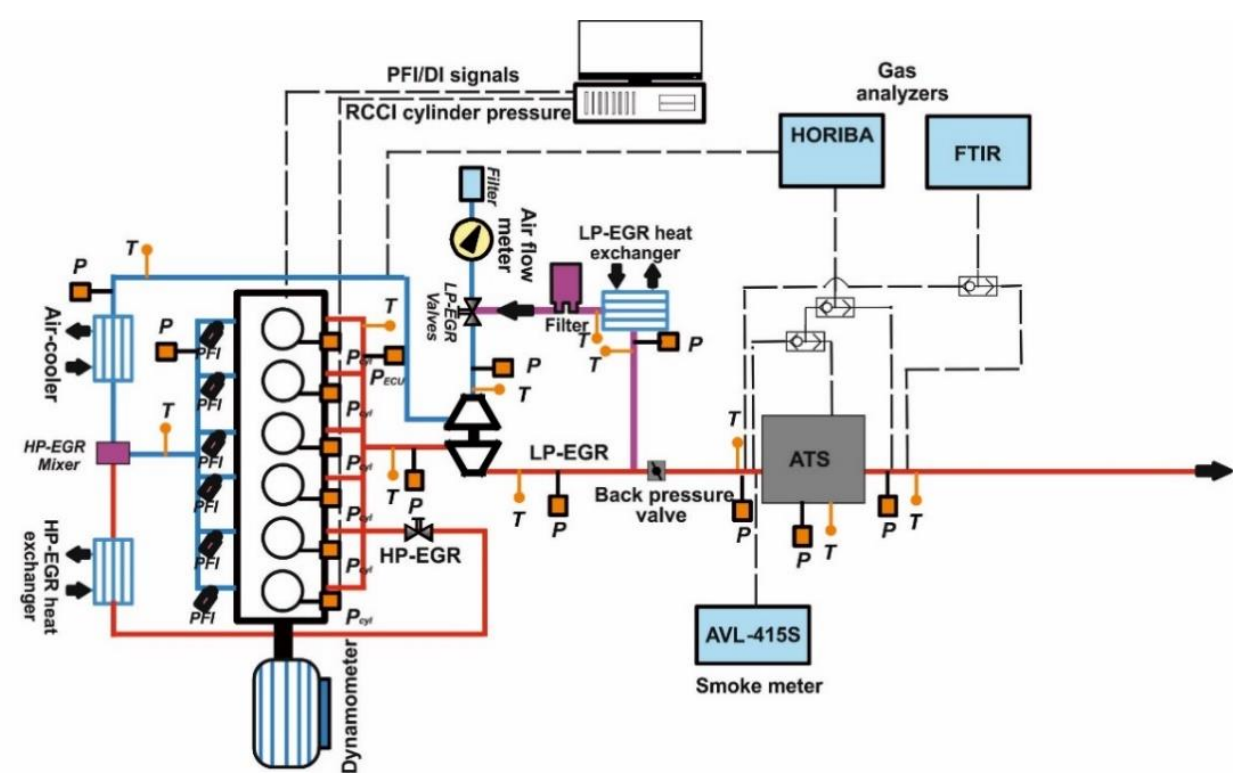

Figure 1. Test cell scheme.

Table 2. Characteristics of the diesel oxidation catalyst used in this work.

\begin{tabular}{|l|l|}
\hline Diameter $[\mathrm{m}]$ & 0.266 \\
\hline Length $[\mathrm{m}]$ & 0.102 \\
\hline Cell density $[\mathrm{cpsi}]$ & 400 \\
\hline Total volume $\left[\mathrm{dm}^{3}\right]$ & 5.7 \\
\hline
\end{tabular}

Table 3. Accuracy of the instrumentation used in this work.

\begin{tabular}{|l|l|l|l|}
\hline Variable measured & Device & Manufacturer / model & Accuracy \\
\hline In-cylinder pressure & Piezoelectric transducer & Kistler / 6125C & \pm 1.25 bar \\
\hline Intake/exhaust pressure & Piezorresistive transducers & Kistler / 4045A & \pm 25 mbar \\
\hline $\begin{array}{l}\text { Temperature in settling } \\
\text { chambers and manifolds }\end{array}$ & Thermocouple & TC direct / type K & $\pm 2.5^{\circ} \mathrm{C}$ \\
\hline Crank angle, engine speed & Encoder & AVL / 364 & $\pm 0.02 \mathrm{CAD}$ \\
\hline $\mathrm{NOx}, \mathrm{CO}, \mathrm{UHC}, \mathrm{O}_{2}, \mathrm{CO}_{2}$ & Gas analyzer & $\begin{array}{l}\mathrm{HORIBA} / \mathrm{MEXA} 7100 \\
\text { DEGR }\end{array}$ & $4 \%$ \\
\hline FSN & Smoke meter & AVL / 415 & $\pm 0.025 \mathrm{FSN}$ \\
\hline Gasoline/diesel fuel mass flow & Fuel balances & AVL / 733S & $\pm 0.2 \%$ \\
\hline Air mass flow & Air flow meter & Elster / RVG G100 & $\pm 0.1 \%$ \\
\hline
\end{tabular}

\subsection{Fuels and injection systems characteristics}

The fuels used to enable RCCI operation were EN 590 diesel (high reactivity fuel) and EN 228 gasoline with 95 research octane number (RON) (low reactivity fuel). Table 4 summarizes the most relevant properties of each fuel. A solenoid injector, with a central position in the combustion chamber, was used to inject the diesel fuel into the cylinder. The fuel was supplied at the desired pressure using the stock common-rail system. The gasoline was port fuel injected by means of a port fuel injector (PFI) located at the intake manifolds. All the injectors were managed using a DRIVVEN control system [40]. The injected quantity of both fuel was measured using independent AVL 733S fuel balances. 
A scheme of the injection systems is shown in Figure 2. Table 5 shows the most relevant characteristics of the injection systems used.

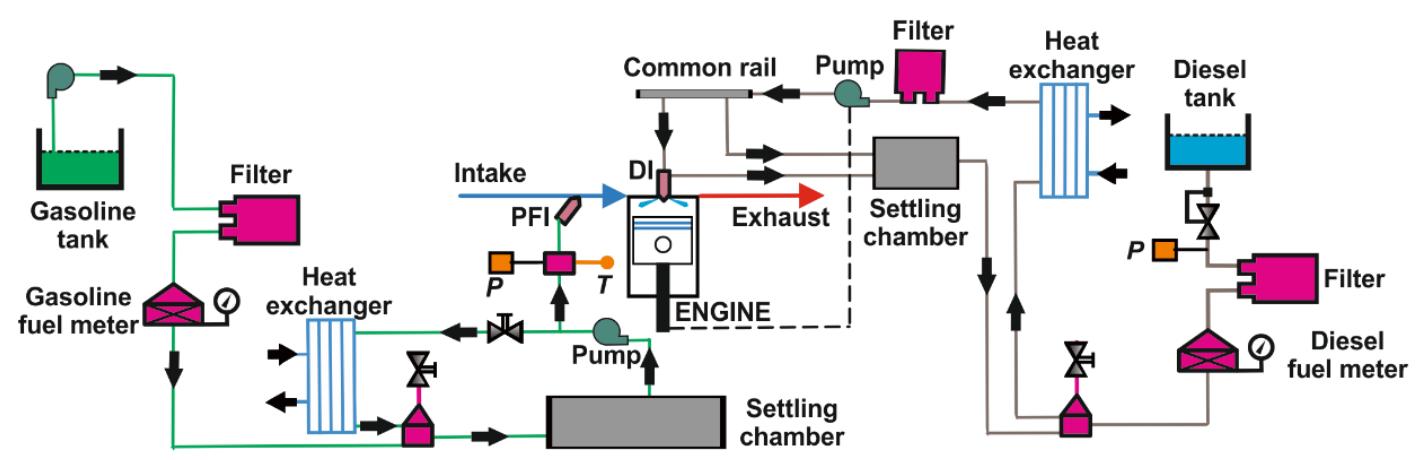

Figure 2. Fuel injection systems scheme.

Table 4. Physical and chemical properties of the fuels.

\begin{tabular}{|l|c|c|}
\cline { 2 - 3 } \multicolumn{1}{c|}{} & EN 590 diesel & EN 228 gasoline \\
\hline Density $\left[\mathrm{kg} / \mathrm{m}^{3}\right]\left(\mathrm{T}=15^{\circ} \mathrm{C}\right)$ & 842 & 720 \\
\hline Viscosity $\left[\mathrm{mm}^{2} / \mathrm{s}\right]\left(\mathrm{T}=40^{\circ} \mathrm{C}\right)$ & 2.929 & 0.545 \\
\hline RON $[-]$ & - & 95.6 \\
\hline MON $[-]$ & - & 85.7 \\
\hline Cetane number $[-]$ & 51 & - \\
\hline Lower heating value $[\mathrm{MJ} / \mathrm{kg}]$ & 42.50 & 42.4 \\
\hline
\end{tabular}

Table 5. Characteristics of the direct and port fuel injectors.

\begin{tabular}{|l|c|l|c|}
\hline \multicolumn{2}{|c|}{ Direct injector } & \multicolumn{2}{c|}{ Port fuel injector } \\
\hline Actuation Type [-] & Solenoid & Injector Style [-] & Saturated \\
\hline Steady flow rate @ 100 bar $\left[\mathrm{cm}^{3} / \mathrm{min}\right]$ & 1300 & Steady flow rate @ 3 bar $\left[\mathrm{cm}^{3} / \mathrm{min}\right]$ & 980 \\
\hline Included spray angle $\left[{ }^{\circ}\right]$ & 150 & Included Spray Angle $\left[{ }^{\circ}\right]$ & 30 \\
\hline Number of holes [-] & 7 & Injection Strategy [-] & single \\
\hline Hole diameter [ $\mu \mathrm{m}]$ & 177 & Start of Injection [CAD ATDC] & 340 \\
\hline Maximum injection pressure [bar] & 2500 & Maximum injection pressure [bar] & 5.5 \\
\hline
\end{tabular}

\subsection{Combustion strategy description}

As literature shows, a typical requirement for the $\mathrm{RCCl}$ combustion is to achieve engineout NOx levels below the limits imposed by the current standards (EURO VI, EPA...) together with negligible soot emissions and high efficiency [16]. However, it has been confirmed that is not possible to obtain a proper calibration that meets these requirements along the whole engine map without exceeding the maximum PRR at high loads. To avoid this problem, Benajes et al. [32] developed the dual-mode dual-fuel (DMDF) strategy, whose injection/combustion strategy is sketched in Figure 3.

The DMDF concept relies on covering the whole engine map with a dual-fuel combustion, but modifying the fuel injection strategy as load increases. At low load, RCCI is implemented using a highly advanced diesel injection strategy, which leads to highly premixed in-cylinder conditions before the combustion start. As shown in the 
performance and engine-out emissions maps reported in [32], this strategy results in simultaneous ultra-low NOx and soot emissions. As engine load increases, the second diesel pulse must be shifted towards TDC to avoid excessive PRR. In the mid portion of the engine map, the NOx emissions are still under the EURO VI levels, but soot emissions start to be penalized due to the lower mixing time for the second diesel injection. At high load, a diffusive dual-fuel strategy must be implemented to avoid excessive PRR. In this area, the peak NOx and soot values are around $1.5 \mathrm{~g} / \mathrm{kWh}$, as those found during CDC.

The main challenge with the DMDF combustion strategy are the high levels of engineout UHC and CO emissions and low exhaust temperatures up to 8-10 bar IMEP, which could compromise the DOC performance, and therefore the potential of the concept to be implemented in real engines. By this reason, this paper is focused on studying this portion of the engine map.
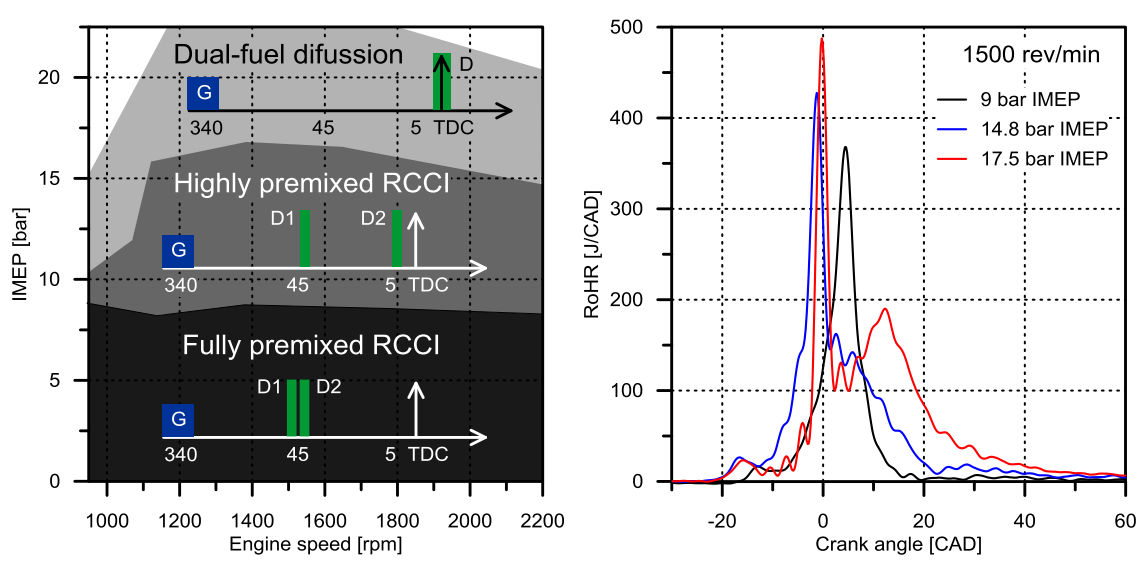

Figure 3. Injection/combustion strategies used to cover the engine map (left) and examples of the RoHR traces from each combustion strategy at $1500 \mathrm{rev} / \mathrm{min}$ (right) [32].

\section{Results and discussion}

The results are divided into two subsections to evaluate the DOC conversion efficiency in steady-state and transient conditions, respectively.

\subsection{DOC conversion efficiency in steady-state conditions}

In this subsection, the DOC response is evaluated in steady-state conditions at $1800 \mathrm{rpm}$ and $10 \%, 25 \%$ and $50 \%$ engine load $(3.8,6.8$ and 12.5 bar IMEP), where the $\mathrm{RCCl}$ strategy presents high levels of unburned products and low temperature. A steady-state condition is defined as that in which the DOC outlet temperature variation is lower than $1^{\circ} \mathrm{C} / 120 \mathrm{~s}$. The engine settings used to perform the tests come from an optimized engine calibration looking for the lowest possible brake specific fuel consumption (BSFC) with simultaneous low NOx and soot emissions [32]. The main engine settings are shown in Table 6, where GF is calculated as shown in Equation 2.

$$
G F[\%]=m_{\text {gas }} /\left(m_{\text {dies }}+m_{\text {gas }}\right)
$$


Table 6. Engine settings used to evaluate the DOC response in steady-state conditions at $1800 \mathrm{rpm}$.

\begin{tabular}{|l|c|c|c|}
\cline { 2 - 4 } \multicolumn{1}{c|}{} & $10 \%$ load & $25 \%$ load & $50 \%$ load \\
\hline IMEP [bar] & 3.6 & 6.8 & 12.5 \\
\hline Exhaust temperature $\left[{ }^{\circ} \mathrm{C}\right]$ & 203 & 311 & 318 \\
\hline Diesel SOI [CAD ATDC] & $-22 /-11$ & $-32 /-22$ & $-60 /-50$ \\
\hline Diesel Pinj $[$ bar] & 800 & 800 & 800 \\
\hline GF [\%] & 0 & 44.2 & 79.7 \\
\hline EGR [\%] & 52.3 & 39.75 & 41.79 \\
\hline
\end{tabular}

Figure 4 shows the UHC and CO emissions measurements before and after the DOC as well as the calculated conversion efficiency (Equation 3). The DOC inlet temperature is also shown in the figure. The left subfigure reveals that, in spite of the high amount of engine-out $\mathrm{CO}$ emissions, the CO levels after the DOC are lower than that imposed by the EURO VI regulation. This is possible thanks to the $100 \%$ conversion efficiency achieved for this pollutant. These results are more promising than those found by Prikhodko et al. [38], who reported no catalytic activity for $\mathrm{CO}$ nor for $\mathrm{HC}$ at temperatures below $300^{\circ} \mathrm{C}$ when operating in steady-state $\mathrm{RCCl}$ conditions. Regarding the UHC emissions, it is seen that the conversion efficiency at $10 \%$ and $25 \%$ load is not high enough to fulfill the EURO VI requirements due to the high engine-out levels. At $50 \%$ load, the engine-out UHC levels decrease by $56 \%$ and the conversion efficiency increases by $3.4 \%$ as compared to $25 \%$ load, which allows reaching the EURO VI levels at the tailpipe. As it can be seen, the DOC inlet temperature for $50 \%$ load is similar to that of $25 \%$, but provides slightly higher UHC conversion efficiency even using higher GF percentages. This is expected to be consequence of the lower UHC levels at the DOC inlet in the case of $50 \%$ load, which reduces the inhibition effects that occur with high concentrations. The results at $50 \%$ load confirm the effectiveness of the DOC in oxidizing the $\mathrm{UHC}$ from $\mathrm{RCCl}$ at high temperatures, even when the major composition comes from the gasoline fuel. These results evidence the need of investigating the influence of the DOC inlet temperature conditions on the DOC performance, as done in the next subsection.

$$
\text { Conversion efficiency }=100 \cdot\left(\frac{\left(Y_{\text {inlet }}-Y_{\text {outlet }}\right)}{Y_{\text {inlet }}}\right)
$$

Where $\mathrm{Y}$ is the mass fraction of the specie under analysis. 

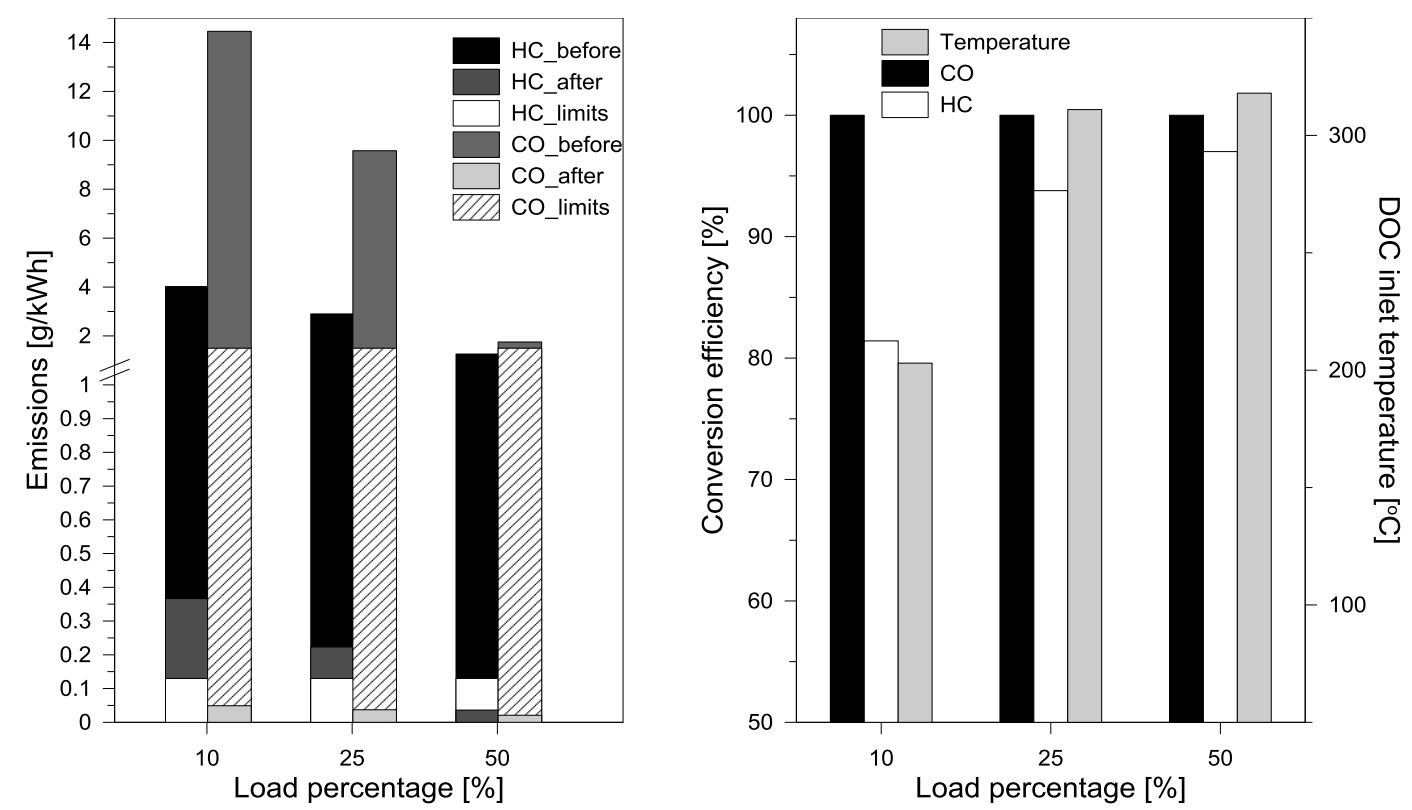

Figure 4. UHC and CO emissions measurements in steady-state conditions before and after the DOC (left). UHC and CO conversion efficiency (right).

\subsection{DOC conversion efficiency in transient conditions}

To evaluate the DOC performance in transient conditions, four different tests are presented in this section. The first two tests are based on performing engine load-speed steps in different conditions. The other two tests represent simplified conditions of the supplemental engine transient cycle (SET) and the worldwide harmonized vehicle cycle (WHVC).

Figure 5 shows the results for an engine load-speed step from CDC to RCCI. As shown in subfigure $5 \mathrm{a}$, the initial condition is CDC at $50 \%$ load and $1800 \mathrm{rpm}$ (12.4 bar IMEP), and the final condition is $\mathrm{RCCl}$ at $10 \%$ load and $950 \mathrm{rpm}$ ( 2.3 bar IMEP). From subfigure $5 \mathrm{~d}$, it is seen that the DOC has $100 \%$ conversion efficiency for CO after promoting the loadspeed step, achieving CO tailpipe emissions lower than the limit imposed by the EURO VI regulation (subfigure 5c). This finding agrees with the results shown in [38], which shows full conversion of $\mathrm{CO}$ for inlet DOC temperatures greater than $150^{\circ} \mathrm{C}$ when operating in transient conditions. Regarding UHC emissions, subfigure $5 \mathrm{~d}$ reveals good conversion efficiency during the next 950 seconds after promoting the load-speed step. As shown in subfigure $5 b$, the UHC oxidation in the DOC provokes an exothermic reaction, being the $D O C$ outlet temperature higher than that at the $D O C$ inlet during this period. When the DOC inlet temperature diminishes below $200^{\circ} \mathrm{C}$, the $\mathrm{UHC}$ oxidation reactions inside the $\mathrm{DOC}$ reduce drastically, provoking an exponential decay of the conversion efficiency with the time. Prikhodko et al. [38] also found the maximum UHC conversion efficiency rates for inlet $\mathrm{DOC}$ temperatures greater than $300^{\circ} \mathrm{C}$, with poor catalytic activity below $200^{\circ} \mathrm{C}$. Finally, looking at subfigure $5 \mathrm{c}$ it is seen that in the period in which the DOC has good conversion efficiency for UHC, the tailpipe levels remains near the regulation limit, but being slightly higher. When the UHC conversion efficiency decays, the tailpipe levels increase near 15 times. 

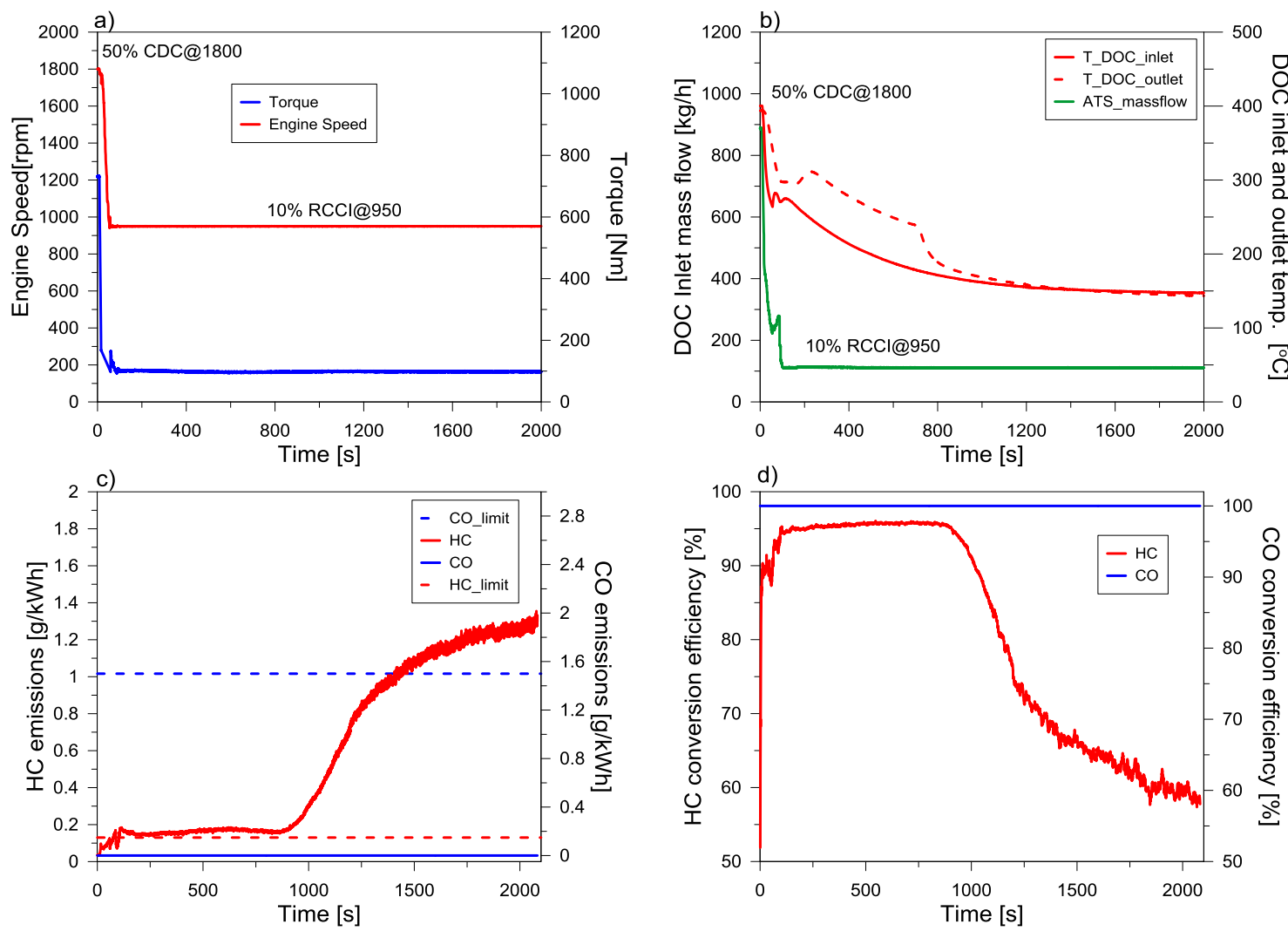

Figure 5. DOC response for an engine load-speed step from 50\% CDC @1800rpm to 10\% RCCI @ 950

rpm.

Figure 6 shows the results for two consecutive engine load-speed steps. As shown in subfigure $6 a$, the initial condition is CDC at $50 \%$ load and $1800 \mathrm{rpm}$ (12.4 bar IMEP), the middle condition is $\mathrm{RCCl}$ at $25 \%$ load and $1500 \mathrm{rpm}$ (6.6 bar IMEP), and the final condition is $\mathrm{RCCl}$ at $10 \%$ load and $950 \mathrm{rpm}$ ( 2.3 bar IMEP). Subfigure $6 \mathrm{~d}$ shows that the DOC conversion efficiency for $\mathrm{CO}$ is $100 \%$ during the entire test, which allows reaching the EURO VI limits for CO at the tailpipe (subfigure 6c). In terms of UHC emissions, subfigure $6 \mathrm{~d}$ confirms the good conversion efficiency during 1600 seconds after the first load-speed step. As a result, the tailpipe UHC emissions levels are below the EURO VI regulation limits up to 1400 seconds. The exothermic reactions in the DOC are confirmed in subfigure $6 \mathrm{~b}$, where an almost constant difference of $\approx 42^{\circ} \mathrm{C}$ is observed between the inlet and outlet DOC temperature. After this time, the DOC inlet temperature drops below $200^{\circ} \mathrm{C}$ and the oxidation reactions inside the DOC slow down. 

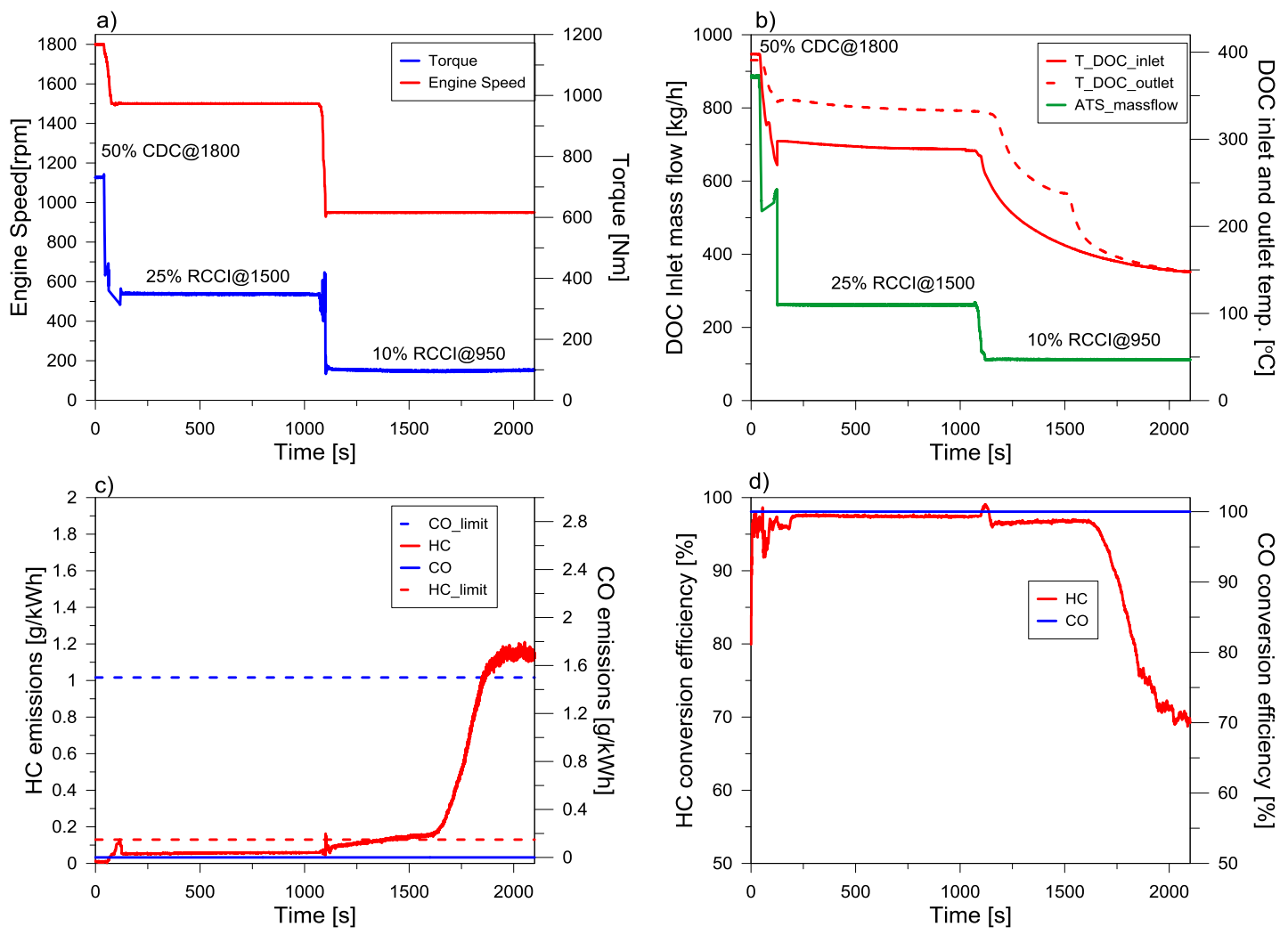

Figure 6. DOC response for a two consecutive engine load-speed steps: from 50\% CDC @1800 rpm to 25\% RCCI @ 1500 rpm, later to 10\% RCCI @ 950 rpm.

The steps proposed in Figures 5 and 6 have a large duration $(\approx 2200 \mathrm{~s})$ to characterize the light-off temperature of the DOC and to evaluate the time during which the conversion efficiency is high (>95\%). However, as can be seen in Figure 7, these lengthy steps are not representative of the conditions found during real driving conditions. To evaluate the DOC response in more real conditions, an additional step is proposed next. The step under study is a simplification of a condition occurring during the urban phase of the WHVC cycle, as highlighted in Figure 7. During this period, the engine load is decreased from 12 bar IMEP to idle, and after 273 seconds with two soft accelerations, the engine load is increased to the initial condition. This process can be simplified as a single load-speed step neglecting the two accelerations to 2 bar IMEP observed in the middle of this period, as illustrated in Figure $8 \mathrm{a}$.

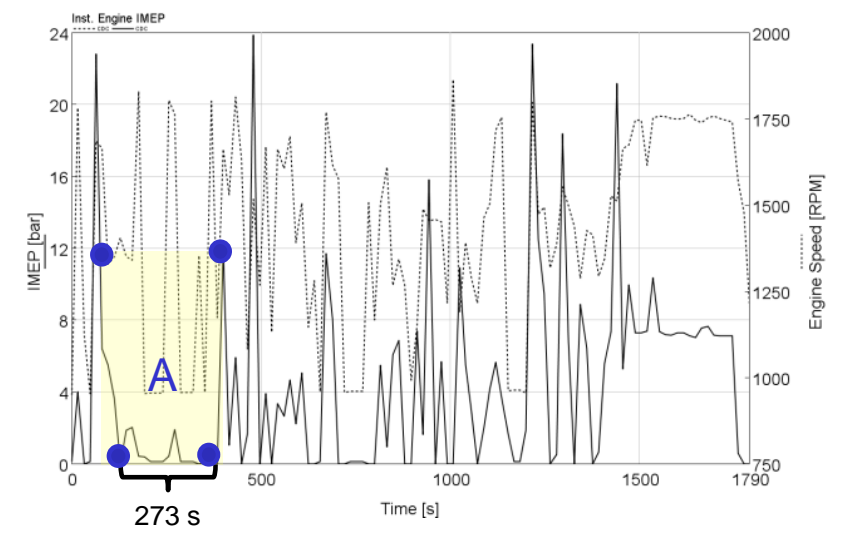

Figure 7. Engine speed and IMEP traces as a function of the time for the WHVC. The load-speed step selected to be studied is highlighted in the figure. 
Figure 8 illustrates the results for two consecutive engine load-speed steps, representative of the WHVC area highlighted in Figure 7. As shown in subfigure 8a, the initial condition is CDC at 50\% load and $1800 \mathrm{rpm}$ (12.4 bar IMEP), the middle condition is $\mathrm{RCCl}$ at $10 \%$ load and $950 \mathrm{rpm}$ (2.3 bar IMEP), and the final condition is the same than the initial one. As expected considering the results shown in Figure 5, the CO conversion efficiency is $100 \%$ during all the experiment. Moreover, it is seen that UHC conversion efficiency is near $95 \%$ all the time. Since the second step is done in a lower time than the critical one (800 s considering subfigure $5 c$ ), the tailpipe UHC emissions are not penalized. Therefore, both emissions are below the EURO VI limits during the 550 seconds (subfigure 8c). During the experiments, the transition between the operating points is done manually, so that the engine control is not perfect and the UHC peaks that are out of the EURO VI level in subfigure $8 \mathrm{c}$ must be neglected. Finally, subfigure $8 \mathrm{~b}$ shows that the DOC outlet temperature is higher than the inlet one during the oxidation reactions. Later, when the second step is promoted, the DOC inlet temperature increases due to the CDC condition, while the outlet temperature is lower than that due to the low amount of UHC emitted by the CDC operating condition.
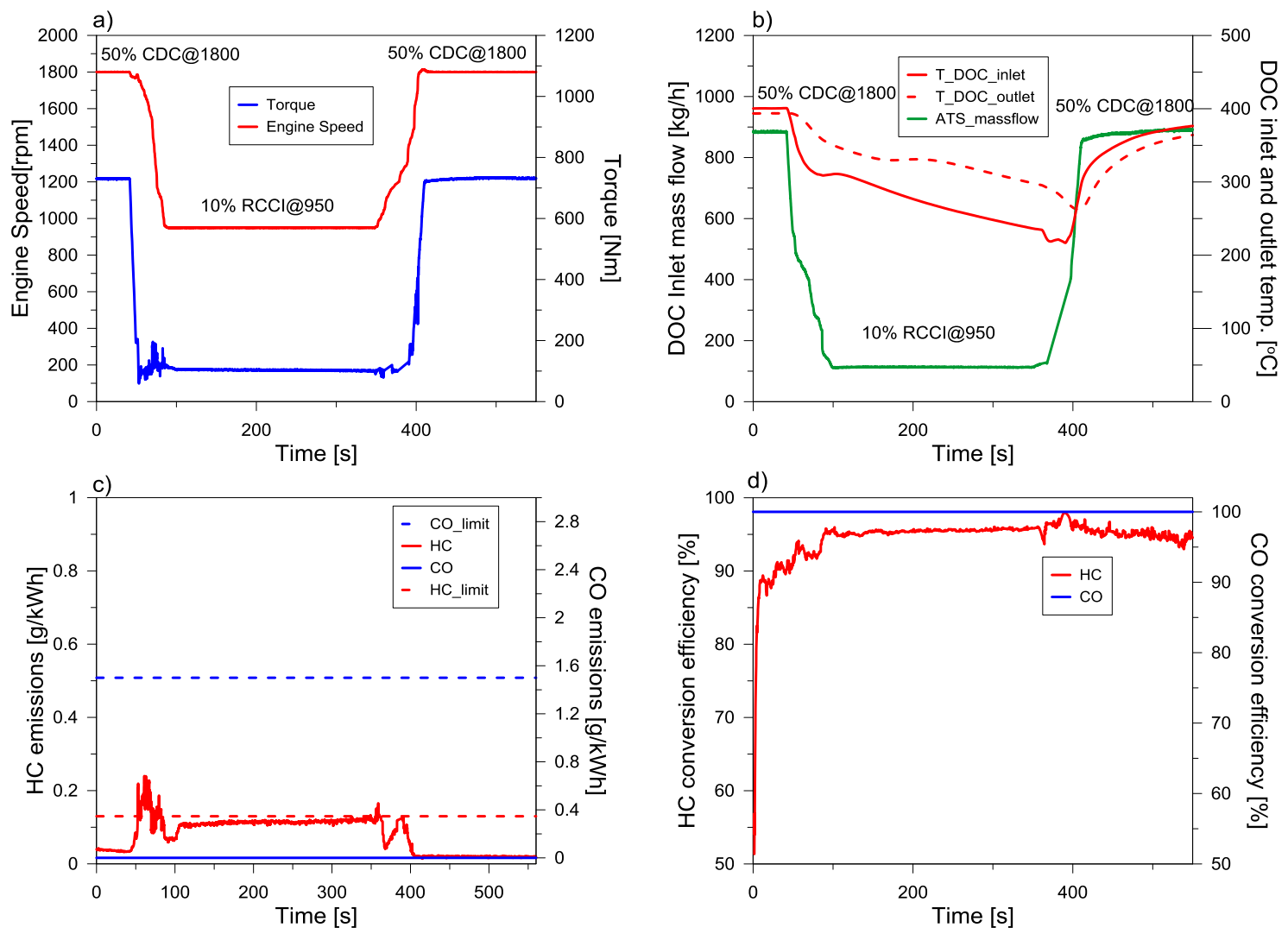

Figure 8. DOC response for a WHVC condition evaluation for a part of urban phase.

To assess the DOC performance in a wider range of operating conditions, an easily implementable engine cycle was selected for the study. Figure 9 shows the speed and load traces as a function of the time for the SET cycle. To perform the experiment, the original SET cycle was scaled to a reduced load (Figure 9) to make the operating conditions falling inside the $\mathrm{RCCl}$ operating region (Figure 3). Then, the scaled SET cycle was implemented manually in the test bench. 


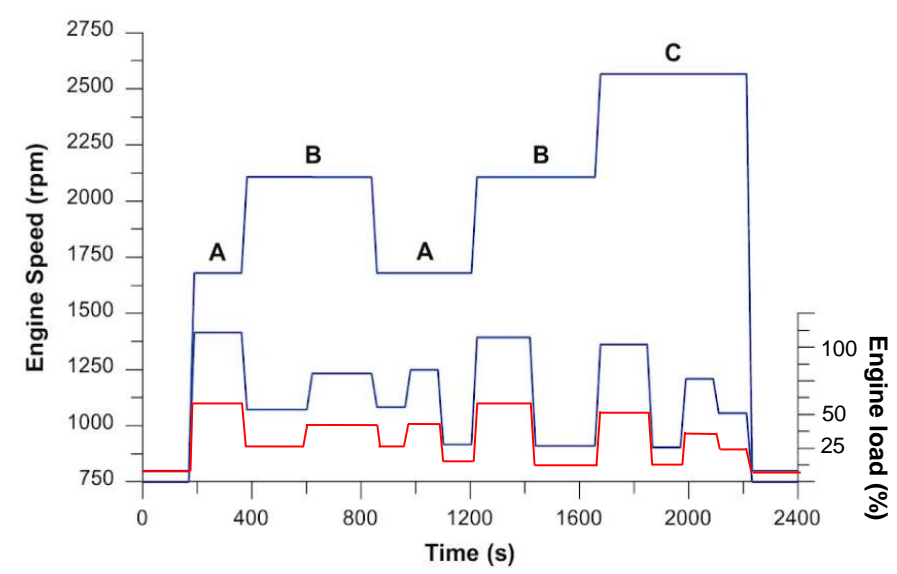

Figure 9. Engine speed and load traces as a function of the time for the SET cycle. The scaled cycle selected to be studied is depicted in the figure.

Figure 10 illustrates the results for the scaled SET cycle. At the beginning of the test, the engine oil and water temperature was $80^{\circ} \mathrm{C}$. Moreover, as seen in subfigure $10 \mathrm{~b}$, the DOC temperature was similar. In subfigure $10 \mathrm{~d}$ it is seen that the UHC conversion efficiency is very low during the first 500 seconds. During this period, the DOC has not reached its light-off temperature, so that oxidation reactions do not occur inside it. This can be confirmed looking at subfigure 10b, where the DOC inlet temperature increases exponentially after the first engine load step, but the DOC outlet temperature remains lower than the inlet one in this period. 400 seconds after the cycle start, the DOC inlet temperature surpasses the light-off temperature of $200^{\circ} \mathrm{C}$ and the exothermic reactions start to occur (subfigure 10b). After that, the UHC conversion efficiency is maintained nearly at $90 \%$ during the rest of the cycle (subfigure $10 \mathrm{~d}$ ). It is interesting to note that the conversion efficiency peaks during the accelerations and decelerations are related to sudden changes in the intake air mass flow, which influences the mass fraction of pollutants in the exhaust stream. Regarding the $\mathrm{CO}$ emissions, it seen that conversion efficiency remains near $100 \%$ all the time, with the exception of some conditions at the beginning and the end of each individual step. The high conversion efficiency allows fulfilling the EURO VI limits during all the cycle (subfigure 10d). By contrast, the UHC tailpipe emissions surpass the limit imposed by the regulation, mainly during the initial period of the cycle. This fact raises the necessity of developing strategies to reduce the time needed to achieve the DOC light-off conditions. 

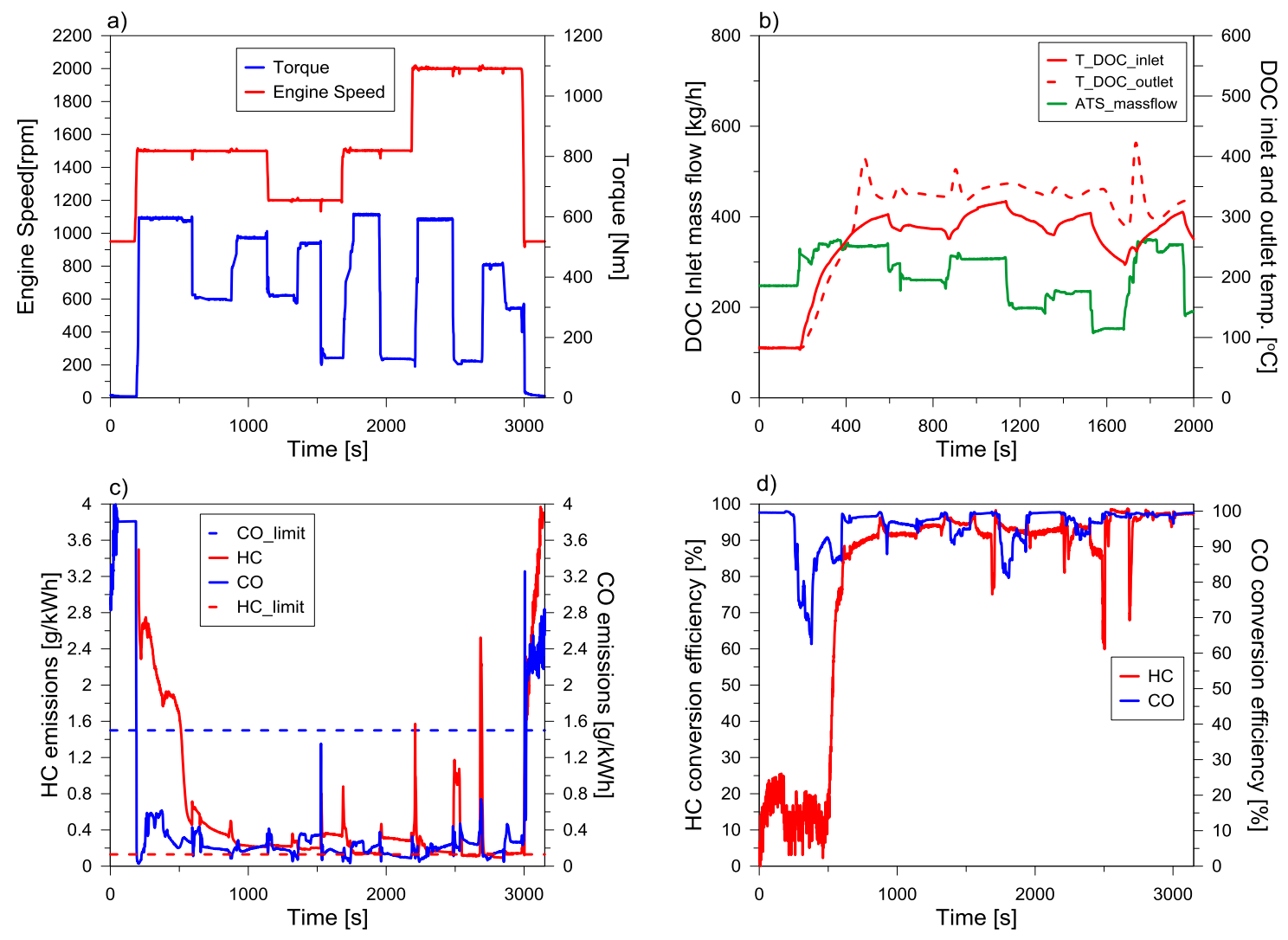

Figure 10. DOC response during the scaled SET cycle.

\section{Conclusions}

This experimental work discussed the response of a conventional DOC when used under $\mathrm{RCCl}$ combustion mode in both steady-state and transient conditions. To do this, a medium-duty multi-cylinder diesel engine equipped with its original aftertreatment system has been used.

In a first step, the DOC response has been evaluated in steady-state conditions at 1800 rpm and $10 \%, 25 \%$ and $50 \%$ engine load. The results show that $\mathrm{CO}$ emissions do not present a problem for the $\mathrm{RCCl}$ concept, because over $200^{\circ} \mathrm{C}$ the DOC can reduce effectively the tailpipe levels below the EURO VI limit. Regarding the UHC emissions, the combination of high emissions levels and low conversion efficiency at $10 \%$ and $20 \%$ engine load resulted in excessive tailpipe levels. The low conversion efficiencies are consequence not only due to the low DOC-inlet temperature, but also to the high UHC levels, which increase the inhibition of the conversion reactions. By contrast, at $50 \%$ load, the engine-out UHC levels decrease and the conversion efficiency increases compared to the lower loads, which allows reaching the EURO VI levels at the tailpipe. Since the DOC-inlet temperature was similar to $25 \%$ load, the lower inhibition is expected to be the reason of the higher conversion efficiency.

In a second step, the DOC response has been evaluated under transient conditions. The different tests confirmed the $100 \%$ conversion efficiency found for CO in steady-state conditions. In terms of UHC emissions, the results improved with respect to those found in steady-state conditions due to the thermal inertia. In the load-speed step done from CDC $1800 / 50 \%$ to RCCI $950 / 10 \%$ the DOC showed UHC conversion efficiencies $>95 \%$ 
during the next 950 seconds, in which the DOC-inlet temperature remained above $200^{\circ} \mathrm{C}$, but with tailpipe values slightly higher than EURO VI. If a double step is done, first to RCCI $950 / 25 \%$ then to RCCI $950 / 10 \%$, the DOC is able to provide EURO VI UHC levels at the tailpipe during 1600 seconds due to the greater thermal inertia of the DOC. Promoting a shorter step, as those found during real driving conditions, the DOC was found to be able to reduce the tailpipe levels below the EURO VI. Finally, the results from an engine cycle starting from cold conditions revealed low UHC conversion efficiency during the first 500 seconds, with values $>90 \%$ after reaching the light-off temperature (around $200^{\circ} \mathrm{C}$ ).

The results shown in this paper raise the necessity of developing strategies to reduce the time needed to achieve the DOC light-off conditions. Moreover, the UHC conversion efficiency must be improved during the regular engine operation to be able to achieve the EURO VI levels. Future works will be focused on refining the engine calibration for lower engine-out UHC emissions and on investigating alternative materials for the wash coat and covering as well as possible modifications of the geometry and number of channels.

\section{Acknowledgments}

The authors thanks VOLVO Group Trucks Technology and ARAMCO Overseas Company for supporting this research. The authors also acknowledge FEDER and Spanish Ministerio de Economía y Competitividad for partially supporting this research through TRANCO project (TRA2017-87694-R).

\section{References}

[1] González J, Otsuka Y, Araki M, Shiga S. Impact of new vehicle market composition on the light-duty vehicle fleet $\mathrm{CO}_{2}$ emissions and cost. Energy Procedia 2017; 105:38623867.

[2] Fontaras G, Dilara P. The evolution of European passenger car characteristics 20002010 and its effects on real-world $\mathrm{CO}_{2}$ emissions and $\mathrm{CO}_{2}$ reduction policy. Energy Policy 2012; 49:719-730.

[3] Araghi Y, Kroesen M, Van Wee B. Identifying reasons for historic car ownership and use and policy implications: An explorative latent class analysis. Transport Policy 2017; 56:12-18.

[4] Garcia A, Monsalve-Serrano J, Heuser B, Jakob M, Kremer F, Pischinger S. Influence of fuel properties on fundamental spray characteristics and soot emissions using different tailor-made fuels from biomass. Energy Conversion and Management 2016; 108:243-254.

[5] Serrano JR, Bermudez V, Piqueras P, Angiolini E. Application of Pre-DPF Water Injection Technique for Pressure Drop Limitation. SAE Technical Paper 2015-010985; 2015. https://doi.org/10.4271/2015-01-0985.

[6] Ettireddy PR, Kotrba A, Spinks T, Boningari T, Smirniotis P. Development of Low Temperature Selective Catalytic Reduction (SCR) Catalysts for Future Emissions Regulations. SAE Technical Paper 2014-01-1520; 2014. https://doi.org/10.4271/2014-01-1520.

[7] Yamauchi T, Takatori Y, Fukuda K. Experimental and Numerical Analysis for a UreaSCR Catalytic Converter. SAE Technical Paper 2016-01-0973; 2016. https://doi.org/10.4271/2016-01-0973. 
[8] Singh N, Rutland C, Foster D, Narayanaswamy K, He Y. Investigation into Different DPF Regeneration Strategies Based on Fuel Economy Using Integrated System Simulation. SAE Technical Paper 2009-01-1275; 2009. https://doi.org/10.4271/2009-01-1275.

[9] Bhardwaj OP, Krishnamurthy K, Blanco-Rodriguez D, Holderbaum B. Comparative Study to Assess the Potential of Different Exhaust Gas Aftertreatment Concepts for Diesel Powered Ultra-Light Commercial Vehicle Applications in View of Meeting BS VI Legislation. SAE Technical Paper 2017-26-0128; 2017. https://doi.org/10.4271/2017-26-0128.

[10] García-Valladolid P, Tunestal P, Monsalve-Serrano J, García A, Hyvönen J. Impact of diesel pilot distribution on the ignition process of a dual fuel medium speed marine engine. Energy Conversion and Management 2017; 149:192-205.

[11] Yanagihara H, Sato Y, Minuta J. A simultaneous reduction in NOx and soot in diesel engines under a new combustion system (Uniform Bulky Combustion System e UNIBUS). In: $17^{\text {th }}$ International Vienna motor symposium; 1996.-14-303, 1996.

[12] Wu HW, Wang RH, Ou DJ, Chen YC, Chen TY. Reduction of smoke and nitrogen oxides of a partial $\mathrm{HCCl}$ engine using premixed gasoline and ethanol with air. Applied Energy 2011; 88(11):3882-3890.

[13] Koci C, Ra Y, Krieger R, Andrie M, et al. Detailed Unburned Hydrocarbon Investigations in a Highly-Dilute Diesel Low Temperature Combustion Regime. SAE Int. J. Engines 2(1):858-879, 2009, doi:10.4271/2009-01-0928.

[14] Harada A, Shimazaki N, Sasaki S. The effects of mixture formation on premixed lean diesel combustion. SAE Technical Paper 980533; 1998.

[15] Kusaka J, Okamoto T, Daisho Y, Kihara R, Saito T. Combustion and exhaust gas emission characteristics of a diesel engine dual- fueled with natural gas. JSAE Review 2000; 21(4):489-496. http://dx.doi.org/10.1016/S0389-4304(00)00071-0.

[16] Kokjohn S L, Hanson R M, Splitter D A, Reitz R D. Fuel reactivity controlled compression ignition (RCCl): a pathway to controlled high-efficiency clean combustion, International Journal of Engine Research 2011; 12:209-226.

[17] Inagaki K, Fuyuto T, Nishikawa K, Nakakita K, Sakata I. Dual-Fuel PCl Combustion Controlled by In-Cylinder Stratification of Ignitability. SAE Technical Paper 2006-010028; 2006.

[18] Benajes J, Molina S, García A, Monsalve-Serrano J. Effects of low reactivity fuel characteristics and blending ratio on low load $\mathrm{RCCl}$ (reactivity controlled compression ignition) performance and emissions in a heavy-duty diesel engine. Energy 2015; 90:1261-1271.

[19] Ryskamp R, Thompson G, Carder D and Nuszkowski J. The Influence of High Reactivity Fuel Properties on Reactivity Controlled Compression Ignition Combustion. SAE Technical Paper 2017-24-0080; 2017.

[20] Li Y, Jia M, Chang Y, Xie M, Reitz R. Towards a comprehensive understanding of the influence of fuel properties on the combustion characteristics of a $\mathrm{RCCl}$ (reactivity controlled compression ignition) engine. Energy 2016; 99:69-82.

[21] Benajes J, Molina S, García A, Monsalve-Serrano J. Effects of Direct injection timing and Blending Ratio on RCCl combustion with different Low Reactivity Fuels. Energy Conversion and Management 2015; 99:193-209. 
[22] Yang Y, Dec J, Dronniou N, Sjöberg M. Tailoring $\mathrm{HCCl}$ heat-release rates with partial fuel stratification: Comparison of two-stage and single-stage-ignition fuels. Proceedings of the Combustion Institute 2011; 33(2):3047-3055.

[23] Curran S, Hanson R, Wagner R. Reactivity controlled compression ignition combustion on a multi-cylinder light-duty diesel engine. International Journal of Engine Research 2012; 13(3):216-225.

[24] Benajes J, García A, Pastor JM, Monsalve-Serrano J. Effects of piston bowl geometry on Reactivity Controlled Compression Ignition heat transfer and combustion losses at different engine loads. Energy 2016; 98: 64-77.

[25] Benajes J, García A, Monsalve-Serrano J, Balloul I, Pradel G. Evaluating the reactivity controlled compression ignition operating range limits in a highcompression ratio medium-duty diesel engine fueled with biodiesel and ethanol. International Journal of Engine Research 2017; 18 (1-2): 66-80.

[26] Park S, Shin D, Park J. Effect of ethanol fraction on the combustion and emission characteristics of a dimethyl ether-ethanol dual-fuel reactivity controlled compression ignition engine. Applied Energy 2016; 182:243-252.

[27] Benajes J, Pastor JV, García A, Boronat V. A RCCl operational limits assessment in a medium duty compression ignition engine using an adapted compression ratio. Energy Conversion and Management 2016; 126:497-508.

[28] Yang B, Yao M, Cheng W, Li Y, Zheng Z, Li S. Experimental and numerical study on different dual-fuel combustion modes fuelled with gasoline and diesel. Applied Energy 2014; 113:722-733.

[29] Li J, Yang W, Goh T, An H, Maghbouli A. Study on RCCl (reactivity controlled compression ignition) engine by means of statistical experimental design. Energy 2014; 78:777-787.

[30] Benajes J, García A, Monsalve-Serrano J, Boronat V. An investigation on the particulate number and size distributions over the whole engine map from an optimized combustion strategy combining $\mathrm{RCCl}$ and dual-fuel diesel-gasoline. Energy Conversion and Management 2017; 140:98-108.

[31] Benajes J, García A, Monsalve-Serrano J, Balloul I, Pradel G. An assessment of the dual-mode reactivity controlled compression ignition/conventional diesel combustion capabilities in a EURO VI medium-duty diesel engine fueled with an intermediate ethanol-gasoline blend and biodiesel. Energy Conversion and Management 2016; 123:381-391.

[32] Benajes J, García A, Monsalve-Serrano J, Boronat V. Achieving clean and efficient engine operation up to full load by combining optimized $\mathrm{RCCl}$ and dual-fuel dieselgasoline combustion strategies. Energy Conversion and Management 2017; 136:142-151.

[33] Benajes J, García A, Monsalve-Serrano J, Villalta D. Exploring the limits of the RCCI combustion concept in a light-duty diesel engine and the influence of the directinjected fuel properties. Energy Conversion and Management 2018; 157:277-287.

[34] García A, Monsalve-Serrano J, Rückert Roso V, Santos Martins M. Evaluating the emissions and performance of two dual-mode RCCl combustion strategies under the World Harmonized Vehicle Cycle (WHVC). Energy Conversion and Management 2017; 149:263-274. 
[35] García A, Piqueras P, Monsalve-Serrano J, Lago Sari R. Sizing a conventional diesel oxidation catalyst to be used for $\mathrm{RCCl}$ combustion under real driving conditions. Applied Thermal Engineering 2018; 140:62-72.

[36] Agarwal A, Pandey A, Gupta A, Aggarwal S, Kushari A. Novel combustion concepts for sustainable energy development. Springer. ISBN 978-81-322-2211-8.

[37] AVL manufacturer manual. Smoke value measurement with the filterpapermethod. Application notes. June 2005 AT1007E, Rev. 02. https://www.avl.com/documents/10138/885893/Application+Notes.

[38] Prikhodko V, Curran S, Parks J, Wagner R. Effectiveness of Diesel Oxidation Catalyst in Reducing HC and CO Emissions from Reactivity Controlled Compression Ignition. SAE Int. J. Fuels Lubr 2013-01-0515; 2013.

\section{Abbreviations}

ATDC: After Top Dead Center

ATS: Aftertreatment System

BSFC: Brake Specific Fuel Consumption

CAD: Crank Angle Degree

CDC: Conventional Diesel Combustion

$\mathrm{Cl}$ : Compression Ignition

CO: Carbon Monoxide

CR: Compression Ratio

DI: Direct Injection

DMDF: Dual-Mode Dual-Fuel

DPF: Diesel Particulate Filter

EGR: Exhaust Gas Recirculation

FSN: Filter Smoke Number

GF: Gasoline Fraction

$\mathrm{HCCl}$ : Homogeneous Charge Compression Ignition

HRF: High Reactivity Fuel

ICE: Internal Combustion Engine

IMEP: Indicated Mean Effective Pressure

LRF: Low Reactivity Fuel

LTC: Low Temperature Combustion

MCE: Multi-Cylinder Engine

NOx: Nitrogen Oxides 
ON: Octane Number

PFI: Port Fuel Injection

PRR: Pressure Rise Rate

RCCl: Reactivity Controlled Compression Ignition

RON: Research Octane Number

SCE: Single Cylinder Engine

SCR: Selective Catalytic Reduction

SET: Supplemental Engine Transient Cycle

TDC: Top Dead Center

UHC: Unburned Hydro Carbons

WHVC: Worldwide Harmonized Vehicle Cycle 